\title{
THE \\ ORTHOPAEDIC REHABILITATION OF A PATIENT AFTER EXCISION OF A CEREBRAL TUMOUR
}

\author{
By Wylie McKissock, O.B.E., M.S., and K. I. Nissen, F.R.C.S.
}

The decision to attempt the salvage of a patient left with severe deformities from spastic paralysis is seldom made easily. It is difficult to predict the gain in function, the surgical procedures may need to be major and multiple, and re-education must be patient and prolonged. On the other hand, an important consideration is the chance of releasing an attendant, often a near relative, from the bondage of constant care. The case reported here is a good example of the problems sometimes encountered.

\section{History}

The patient is a man aged 32 years. In 1924 at the age of six, Sir Percy Sargent explored but was unable to remove a gliomatous cyst of the right parietal region which had been causing symptoms for two years. After the operation he was left with extensive weakness on the left side and a squint, but he continued his education and

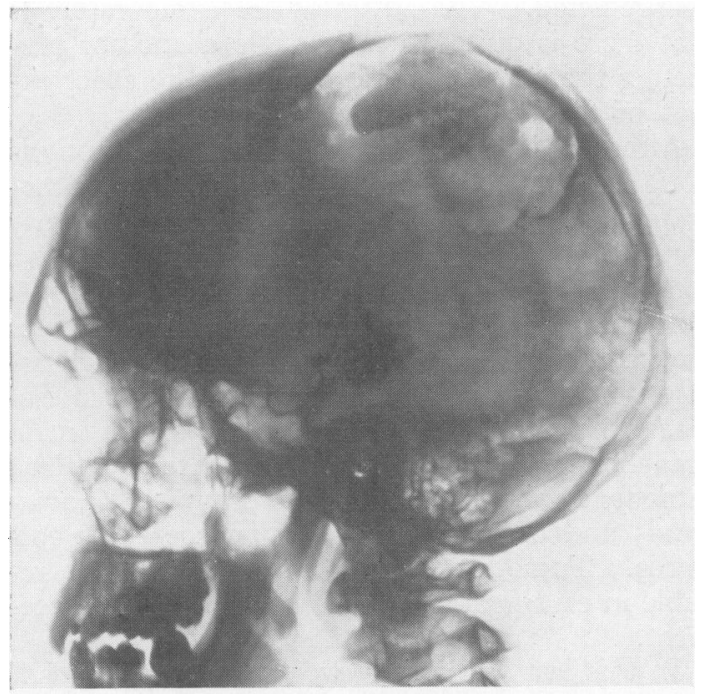

Fig. 1a.-A radiograph taken before the second operation, showing the bone flap of the operation by Sir Percy Sargent and calcification in the gliomatous cyst. finally entered the Civil Service in I94I at the age of 24. Two years later he had the first of four fainting attacks, each with loss of consciousness for a few minutes. All the attacks occurred in the morning; they were preceded by momentary dizziness and followed by extension of the head and neck. There were no headaches and each time he was able to return to work the next day. The weakness of the left side did not increase after any attack.

Apart from the stationary left side, the main findings in 1944 were radiological. There was an old right parietal skull defect, mostly covered by new bone formation, and a large calcified tumoun in the right temporal lobe originating from quite narrow stalk in the middle of the fossa and extend ing well into the parietal region (Fig. ra). In the upper part was a cyst $6 . \mathrm{cm}$. in diameter.

In October 1944 the large cystic tumour was excised at the Atkinson Morley Hospital. Severe

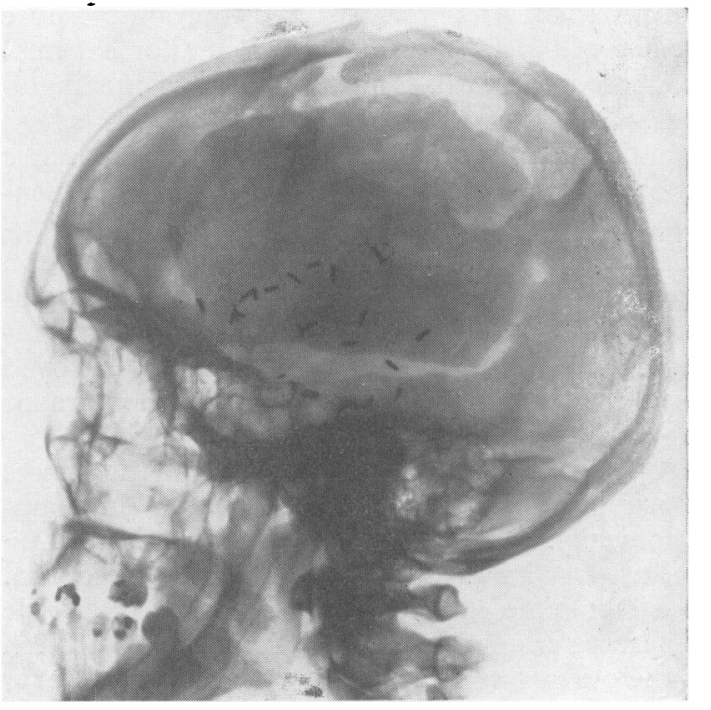

FIG. Ib.-A radiograph taken after the second operation, showing the extensive bone flap, and the silver clips use 1 to control haemorrhage from the temporal fossa and from the choroid plexus. 


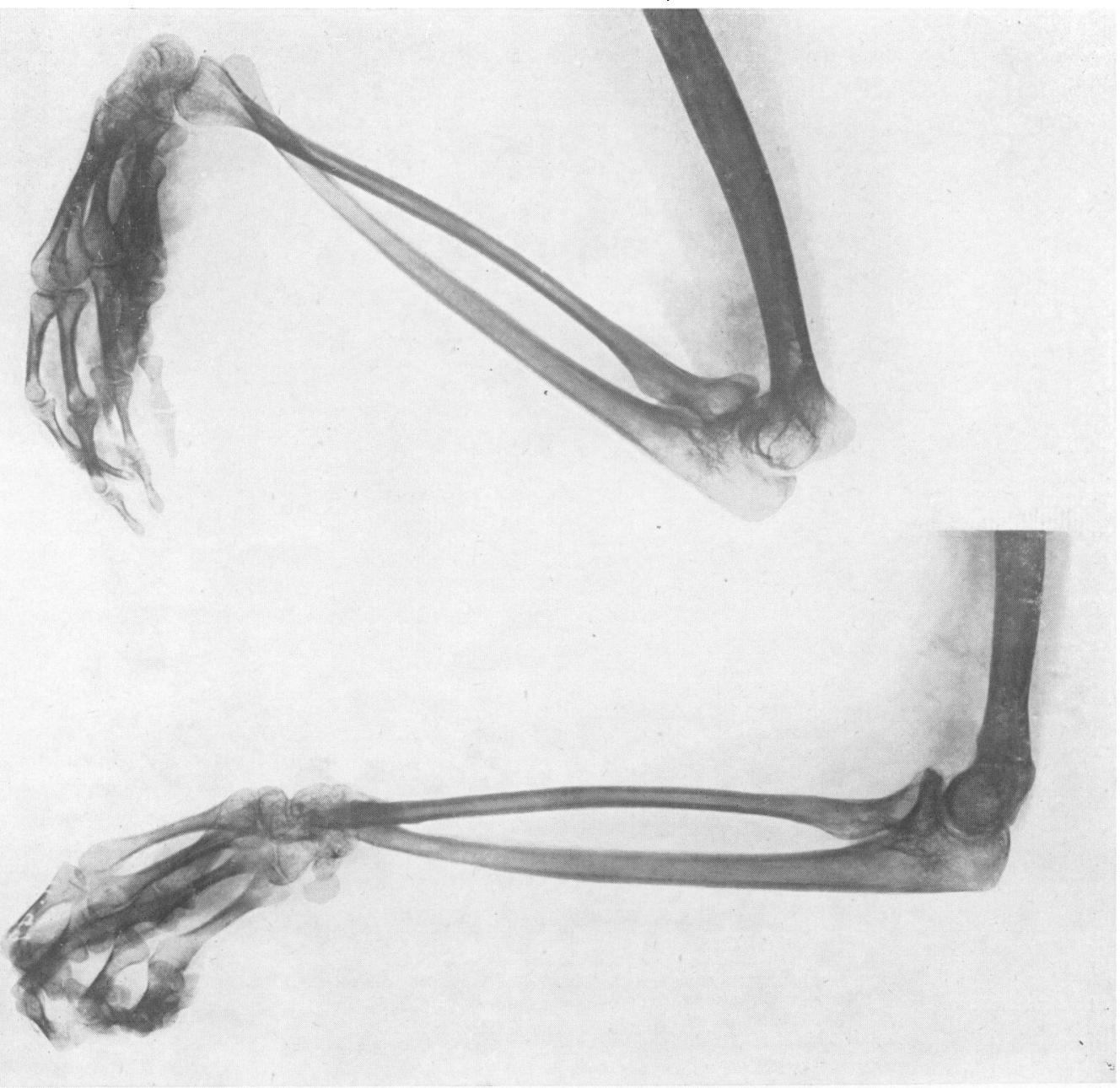

Fig. 2a.-A radiograph of the left arm before operation, showing the maximum degree of voluntary extension of the elbow and of dorsiflexion of the wrist.

FIG. 2b.-A radiograph taken after section of the biceps and brachialis anticus muscles, and 'gouge' arthrodesis of the wrist. The radius, and unintentionally the ulna, are soundly fused with the carpal bones.

arterial bleeding from the deep surface of the temporal lobe was controlled by silver clips. The tumour had invaded the inner wall of the temporal horn, the trigone, and the lateral wall of the ventricle. The temporal part of the choroid plexus was divided between silver clips and removed. The enormous cavity left after excision of the tumour led to collapse of the entire hemisphere and the brain fell away from the cranium for 2 to $3 \mathrm{~cm}$. The whole space was filled with saline and the dural flap was closed in the usual manner. The bone flap was replaced after a moderate decompression at the base.

For several weeks the post-operative state was extremely grave and it was doubted whether the patient would ever rouse from his state of stupor. After five months, however, he could mutter a few words and move the right arm. After one year he was talking freely, and was again continent; four deep pressure sores were healing, but severe contractures had developed in the left arm and in both legs. He was now being cared for at home entirely by his widowed mother, an air-raid warden; he spent part of each day in a chair, but had often been alone at night during the bombing raids. After two years he was so alert and cooperative that he was referred to an orthopaedic centre, but all attempts to correct the deformities of the legs by physical means failed, and he was returned to his upstair bedroom off Streatham Hill. 
Fig. 3.-A radiograph before operation showing dislocation of the left hip and abduction deformity of the right hip, Both trochanters have been eroded from pressure sores. The right lesser trochanter is seen in full profile, indicating a marked degree of external rotation.

\section{Treatment}

Four years after the second brain operation the patient was admitted to the country branch of the Royal National Orthopaedic Hospital, where he was to remain as an in-patient for a year. At first sight the possibility of his ever walking again appeared remote. Though the right arm was powerful, the left arm was wasted and contracted at the elbow and wrist, rather like the wing of a plucked fowl (Fig. 2a). The left leg was almost completely paralysed, with the hip dislocated and the femur internally rotated, flexed and adducted (Fig. 3); the knee was moderately flexed, and the foot was in the equino-varus position. The right leg, less completely paralysed, had been pushed into abduction by the left, and was externally rotated and flexed; the knee showed a flexion contracture of $30^{\circ}$, but the foot, apart from a deep old pressure sore caused by the opposite heel, was in good shape. There were also healed sores adherent to bone over each great trochanter, one ischial tuberosity, and the dorsum of the right foot. The patient was somewhat obese. On the credit side, however, there were intelligent co-operation, a splendid right arm and an optimistic mother.

The order of the seven reconstructive pro- 9 cedures considered necessary for the three limbs was first decided upon, and in the event, except for temporary setbacks at the left wrist and right hip, N the order was adhered to. It was argued that as the prospect of walking depended on obtaining $N$ crutch support from both arms, the left arm should $\mathrm{\omega}$ be made fit for this purpose by bringing it down to a right angle at the elbow, with the wrist $\varrho$ straight. In this position a crutch with a gutter top $\mathbb{D}$ and a bicycle handle-grip set to the angle of the palm can be used to advantage even when the only useful power in the arm is in the shoulder muscles (Fig. 5b). Two operations were needed for the left arm:- 


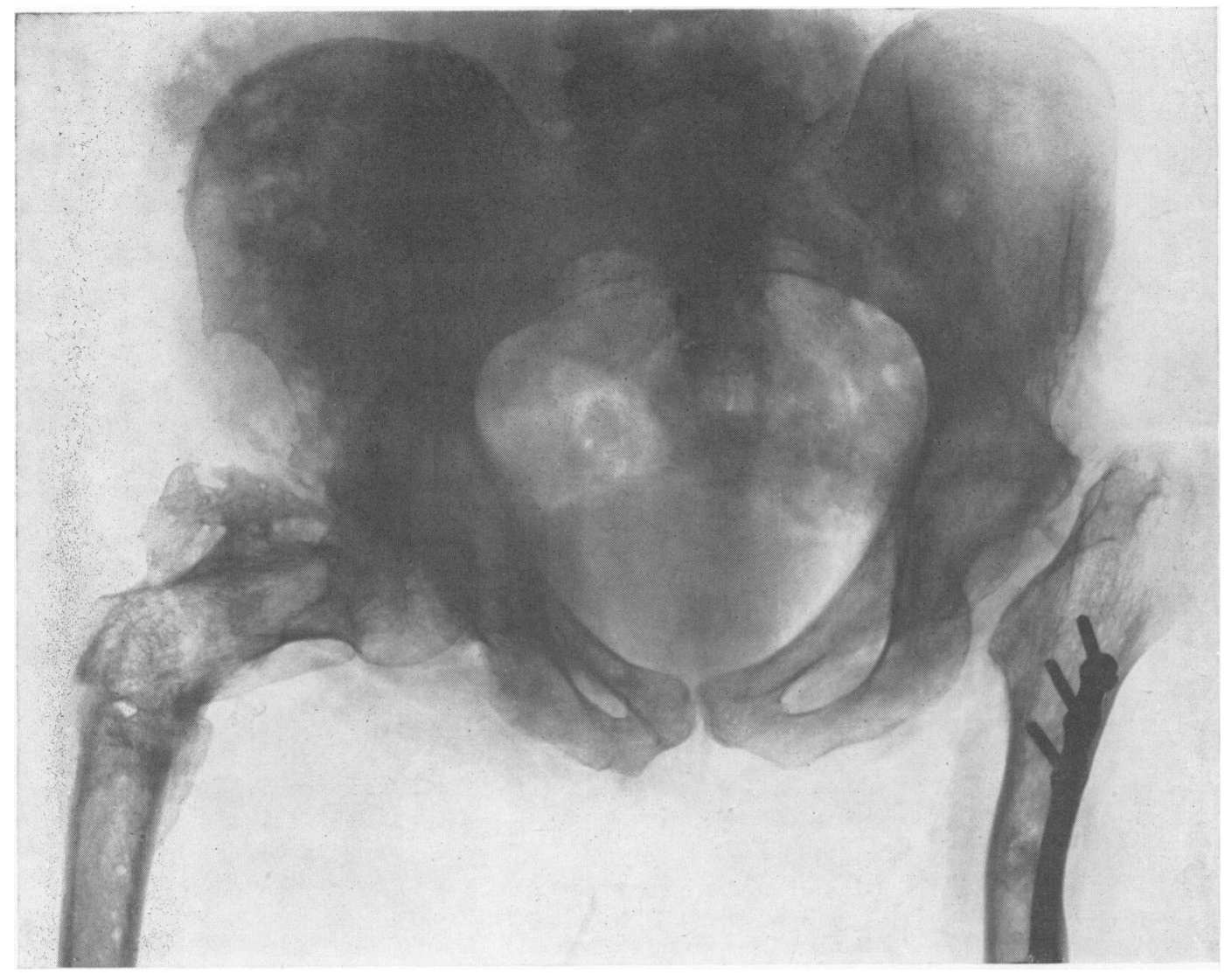

Fic. 4.-A radiograph taken after Batchelor's operation on the left hip, and osteotomy of the right femur (the plate having been removed). The angulation of the remaining plate appears diminished owing to some external rotation of the left leg.

1. Reduction of the flexion contracture of the elbow. A broad V-shaped incision was made in the contracted skin over the front of the joint to allow elongation of the skin and suturing in the shape of a Y. The biceps tendon and all fibres of brachialis anticus were transected. This allowed the forearm to extend to just below the right angle, which position was maintained by plasterof-Paris. The wound took four weeks to heal soundly. End-result: This degree of correction has been maintained. The brachio-radialis muscle now provides sufficient flexor tone to balance the triceps.

2. Arthrodesis of wrist ('gouge' technique). The tendons of the deforming muscles flexor carpi radialis and ulnaris were first divided. A 4-in. mid-line dorsal incision was made over the wrist, and the atrophied extensor tendons were freely mobilized to allow retraction to one side or the other. The distal inch of the ulna was excised in the hope of retaining some range of rotation of the forearm. The lower end of the radius was next bared and fashioned into a gouge with the bevelled side forwards. Both rows of carpal bones were then split in halves in a curved fashion, and the gouge of cancellous bone of the radius was well impacted into them. This left the wrist straight, and a full-arm padded plaster was applied. Despite elevation and ice bags, the post-operative swelling was much greater than usual, and by causing pressure against the cast, disimpacted the radius from the carpus. A month later this was corrected and good impaction was maintained for three months, by which time sound fusion had occurred (Fig. 2b). The lower end of the ulna, however, also shared in the fusion; this meant a fixed position of rotation of the forearm, a matter of little moment and possibly an advantage in a case such as this. End-result: The left arm is now a limb of some practical value. With the special 


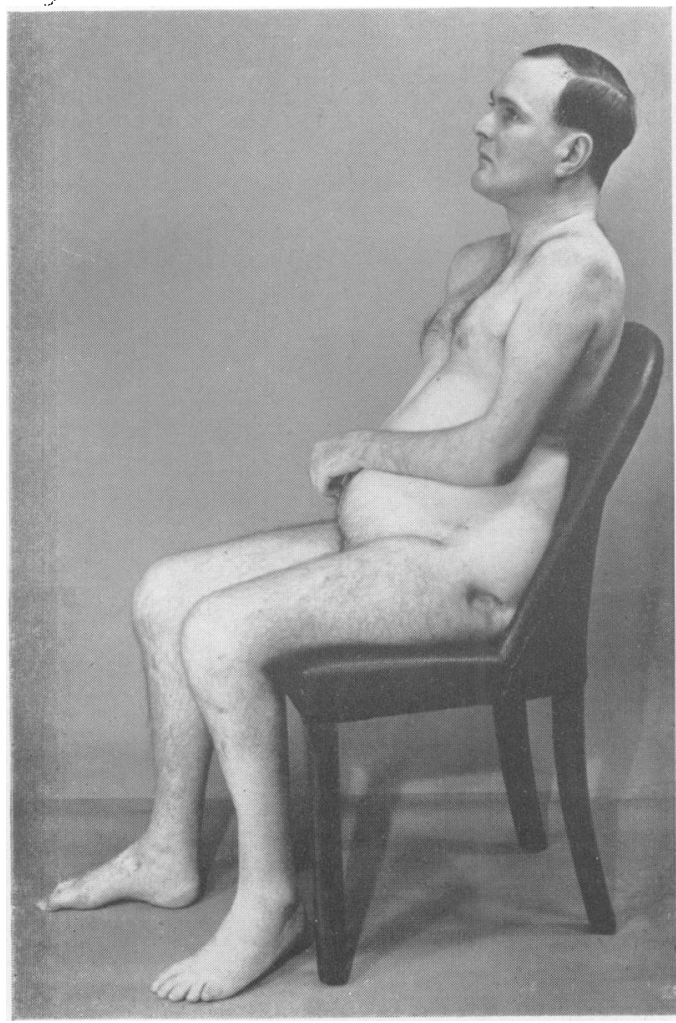

FIG. 5a.-A photograph taken after completion of the surgical programme. The left arm is in a useful attitude, and the flexion range at the hips allows comfortable sitting. Note the healed pressure sores over the great trochanter and on the dorsum of the right foot.

crutch strapped on, the patient can stand alone; with it off, he can use the fist for steadying objects, and even has some weak returning power of grasp.

\section{Treatment of the Left Leg}

With the surgical programme for the arm well in hand, and with the knowledge that short anaesthetics at least were well tolerated, the major procedures for the lower limbs could begin. Obviously the adducted left leg had to be restored to a vertical position where it could act as a prop and where it would allow room for the correction of the abducted left leg. The spastic and contracted adductor muscles needed to be dealt with first, and then some type of arthroplasty had to be performed on the dislocated hip in order to restore sufficient movement to allow both sitting and standing positions. For this type of case, Batchelor's two-stage pseudarthrosis, ${ }^{1}$ so well

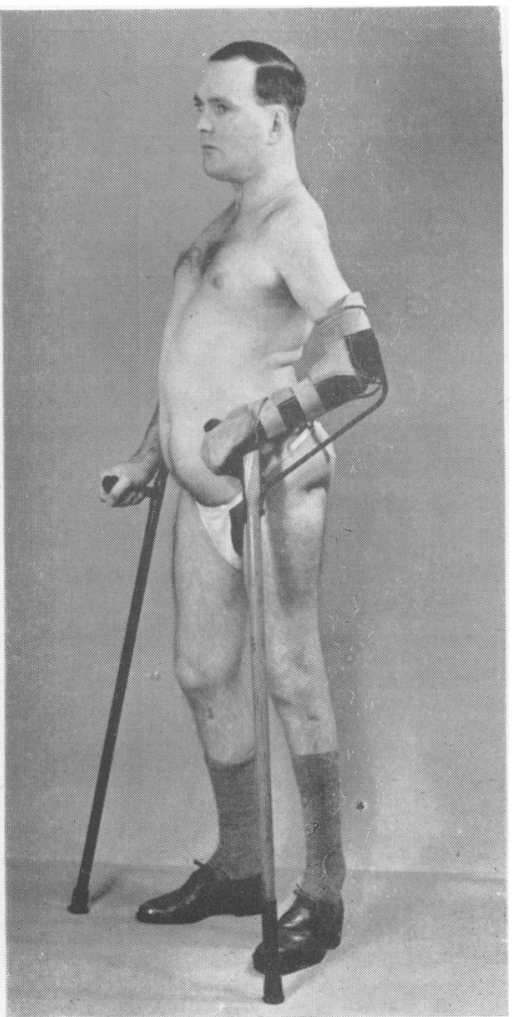

FIG. 5b.-The patient standing with the aid of a special crutch incorporating a padded gutter-splint for the arm, and a bicycle-grip set to suit the palm. 용 The scars of the tibial pins are visible. The left shoe has been raised 2 in. (The squint is due on $\overrightarrow{\overrightarrow{0}}$ the right side to complete paralysis of all muscles 3 except the external rectus, and on the left, to paresis of the internal, superior and inferior recti.)

described in a previous number of this Journal, was the obvious choice.

3. Obturator neurectomy and tenotomy of ad-i் ductors of left hip. Through a median suprapubic incision, and with some difficulty due to masses 0 of retroperitoneal fat, the obturator nerve was? found near the obturator foramen and divided. The adductor tendons were divided subcutaneously close to the pubis, and most of the adduction con- $\sigma$ tracture was reduced by guarded manipulation $N$ of the femur. This position was maintained N simply by putting a sling round each knee and tying them to the sides of the bed.

4. First stage of Batchelor's operation. The left hip joint was exposed by the anterior (SmithPetersen) approach, and the head and neck of the femur were excised. It was then possible to abduct the leg, and the fixed flexion deformity almost disappeared. Post-operatively, skeletali 
traction was secured with a Steinmann's pin through the tibial tuberosity, and a system of stirrups and pulleys which allowed free swinging movement from the overhead beam. ${ }^{2}$ To avoid any recurrence of fixed flexion the patient was nursed flat on the bed for half of each day. After four weeks there was a range of assisted active movement which was surprisingly good in view of the previous absence of voluntary movement at the hip.

5. Second stage of Batchelor's operation. This was performed with the patient lying prone on the operating table, which was broken at the level of the hips by some $20^{\circ}$ in order to relax the psoas muscles. The subtrochanteric osteotomy, with a spike on the distal fragment, was made in the usual way and fixed with a six-hole plate angled about $30^{\circ}$. In this way a plaster spica was avoided, and with skeletal traction as before, swinging movements were again started after four or five days. Radiographs showed sound bony union at eight weeks as usual. End-result: The present range of flexion is from $5^{\circ}$ to $80^{\circ}$; adduction and abduction are each $20^{\circ}$; but some fixed external rotation has developed from the pull of the psoas, the action of which on the lesser trochanter, now that the head and neck are missing, is very similar to that of the normal biceps muscle on the tuberosity of the radius.

\section{Treatment of the Right Leg}

Attention was next paid to the right leg, first to the flexed knee, and then to the hip, which was remaining widely abducted despite the departure of the left leg to the neutral position.

6. Tenotomy of the right hamstrings. The tendons of all the hamstrings were divided through two short vertical incisions just above the knee. With firm pressure, most of the flexion deformity was corrected and a long plaster was applied. At the same time the equino-varus deformity of the left foot was treated by manipulation and plaster, a procedure later repeated twice.

7. Plated osteotomy of right femur. The upper third of the femur was exposed through an incision which encroached on the fibrous scar of an old pressure sore adherent to the trochanter. After section of the upper shaft and correction of the triple deformity of abduction, external rotation and flexion, a plate was twisted to fit the available bone surfaces, and fixed with six screws. Tibial traction was again applied, and both legs were in a normal attitude.

The second setbac's to the programme was now encountered. A low-grade infection developed, most probably owing to the extension of the incision into the region of the old pressure sore.

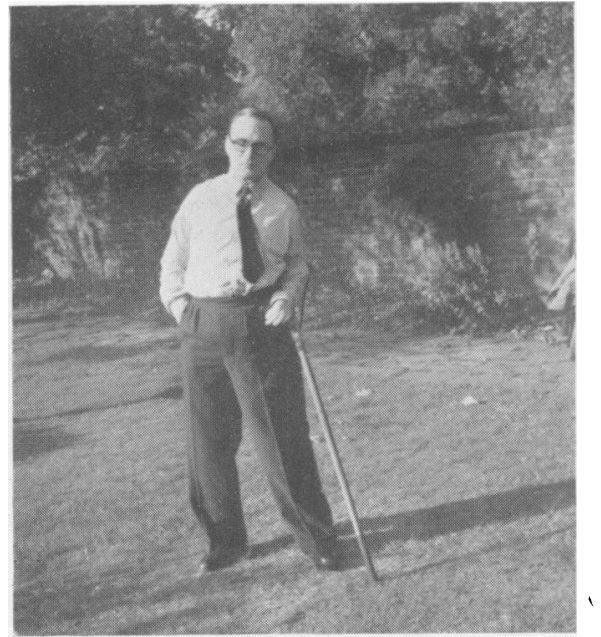

FIG. 6.-A photograph taken six months after discharge from hospital. The persistent lean to the left is well shown. Standing would obviously be impossible without support from the crutch on the badly paralysed left arm. The picture emphasizes the importance of an 'all-or-nothing' programme in cases of this type.

Fortunately bone union was rapid and appeared complete after eight weeks. The plate was then removed and the incision healed by first intention. End-result: The range of movement is as good as that of the right hip.

\section{Progress}

Ten months after admission, exercises in the warm pool were commenced. These went well, but when crutches were first used, the degree of impairment of balance became apparent from the constant pitch of the trunk over to the left side (Fig. 6). This has made rising from a chair without aid a serious difficulty.

Six months after discharge from hospital, the patient is up all day, dresses himself, manages his toilet, and can walk with crutches. A sympathetic housing manager has found a bungalow with a garden. There is talk of a motor chair and clerical work, while his mother, free from the burden she carried for four years, is a changed woman.

\section{Acknowledgments}

The clinical photographs and prints of radiographs are the work of Mr. R. J. Whitley at the Institute of Orthopaedics.

\section{REFERENCES}

I. BATCHELOR, J. S. (1948), Postgrad. Med. Four., 24, 24I. 2. NISSEN, K. I. (1949), Proc. Ro1. Soc. Med. (Section Orthopaedics), November, in press. 